\title{
Duodenal Metastasis of a Cervical Squamous Cells Carcinoma: Case Report
}

\author{
Álvaro Bellido Caparó ${ }^{*}$, Jorge Espinoza Ríos ${ }^{1,2}$, Carlos García Encinas ${ }^{1}$, Medalith Fuentes Rivera-Quinteros ${ }^{3}$, José \\ Luis Pinto Valdivia ${ }^{1,2}$ and Martin Tagle Arróspide ${ }^{2,4}$ \\ ${ }^{1}$ Departament of Gastroenterology, Hospital Cayetano Heredia, Perú \\ ${ }^{2}$ Departament of Medicine, Universidad Peruana Cayetano Heredia, Perú \\ ${ }^{3}$ Departament of Pathology Cayetano Heredia Hospital, Perú \\ ${ }^{4}$ Departament of Gastroenterology, Service of the Clinica Angloamericana, Perú \\ *Corresponding author: Alvaro Bellido Caparó, Departament of Gastroenterology, Hospital Cayetano Heredia, Avenida Honorio Delgado 262, Lima \\ 15102, Peru
}

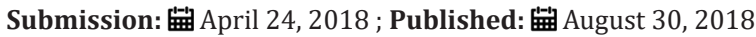

\section{Introduction}

Malignant tumors of the small bowel (SB) represent 1-2\% of the neoplasms of the digestive system, and 30 to $50 \%$ are adenocarcinomas, more frequently located in the duodenum $[1,2]$. Other primary tumors of the SB are lymphoma (15-20\%), carcinoid tumors (5-24\%) and sarcoma. The four mentioned tumors account for $95 \%$ of the malignant SB lesions [3]. Kanthan et al. [2] conclude that malignant and benign lesions of the duodenum are rare, and there could be coexistence of those types of tumors, stressing the importance of early diagnosis of malignant lesions for an adequate patient management [2].

Duodenal metastases are rare, being the periampullary region the most frequently involved, followed by the duodenal bulb. The most frequently reported duodenal metastases is from melanoma [2]. Other sources of reported metastases to the duodenum are renal, lung, thyroid adenocarcinomas, Merckel cell carcinoma and pheochromocytoma [2]. In immunosuppressed patients the most frequent metastases comes from Kaposi's Sarcoma [3]. Metastases from squamous cell carcinoma of the cervix are extremely infrequent [2]. We present the case of a 47 year old patient who presents with a gastric outlet obstruction syndrome, with a history of cercival neoplasia stage IIb and in whom an upper endoscopy revealed a proliferating duodenal lesion. The biopsies taken from the lesion are diagnostic of epidermoid carcinoma.

\section{Case Report}

Forty-seven year-old female with a history of squamous cell carcinoma of the cervix stage IIb 5 years prior to admission, receiving radiotherapy (25 sessions), chemotherapy and brachytherapy. Her periodic controls were negative for recurrence. She presents with 5 month of colicky epigastric pain, worsened by food ingestion, associated with post prandial nausea and vomiting and a 3-kg weight loss. Physical examination was remarkable for moderate pallor, distended abdomen with decreased bowel sounds and epigastric tenderness. Laboratory evaluation was relevant for microcytic hypochromic anemia, urea/creatinine dissociation and hypokalemia (Table 1).

Table 1: Laboratory tests.

\begin{tabular}{|c|c|}
\hline Hemoglobin (g/dL)/VCM (fl)/HCM (pg) & $7.9 / 78 / 27$ \\
\hline WBC/Platelets (x103) & $6590 / 714$ \\
\hline INR & 1.14 \\
\hline Glucose/Urea/Creatinine (mg/dL) & $96 / 31.3 / 0.8$ \\
\hline Sodium/Potassium/Chloride (mg/dL) & $142 / 4.11 / 105$ \\
\hline Proteíns/Albumin (g/dL) & $8.1 / 4.1$ \\
\hline Total Bilirubin/direct/indirect (mg/dL) & $0.5 / 0.3 / 0.2$ \\
\hline AST/ALT (UI) & $36 / 51$ \\
\hline
\end{tabular}

An upper endoscopy was performed and revealed the presence of a large amount of bilious content in the stomach and proximal duodenum. The third portion of the duodenum showed a proliferating violaceous mass, which was friable and completely obstructed the duodenal lumen (Figure 1). A CT scan evidenced a retroperitoneal mass infiltrating the duodenum, and was associated with dilatation of the proximal duodenum and stomach (Figure 2). An exploratory laparoscopy showed 8 x $8 \mathrm{~cm}$ retroperitoneal mass involving the duodenum and para aortic lymph nodes. A palliative gastro jejunostomy bypass was performed. The pathologic study of the biopsies showed epithelial cells with corneal pearls and the immunehystochemistry study was positive for p63, confirming the diagnosis of squamous cell carcinoma of the cervix (Figure $3 \& 4$ ). Our patient improved with the above mentioned palliative bypass surgery 


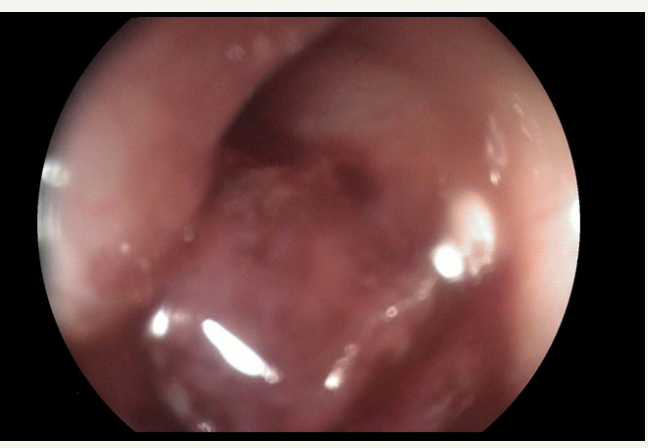

Figure 1: Upper endoscopy showing erythematous -violaceous stenosing and friable lesion in the third portion of the duodenum.

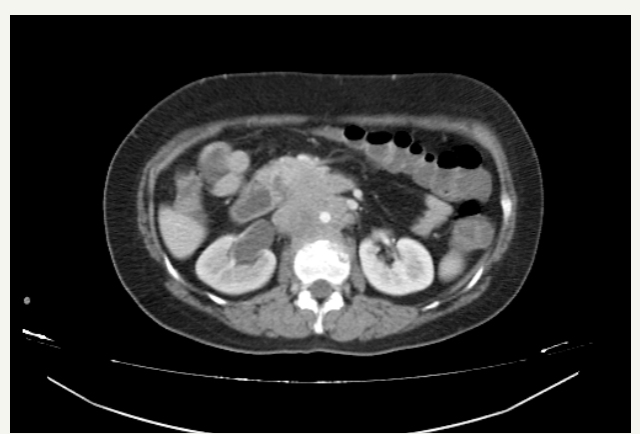

Figure 2: Abdomen and Pelvic CT Scan with contrast showing an infiltrating heterogeneous retroperitoneal lesion involving the duodenal second portion, causing dilatation of the proximal duodenum and stomach. Right sided hydronephrosis is also seen, caused by the retroperitoneal mass.

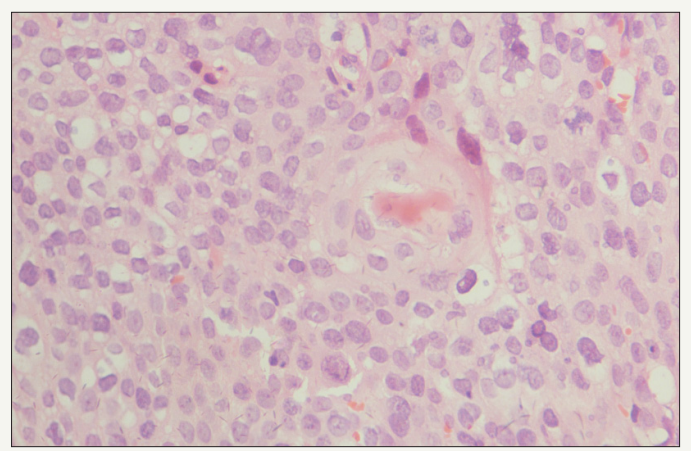

Figure 3: Epithelial cells with hyperchromatic nuclei and Keratin pearl.

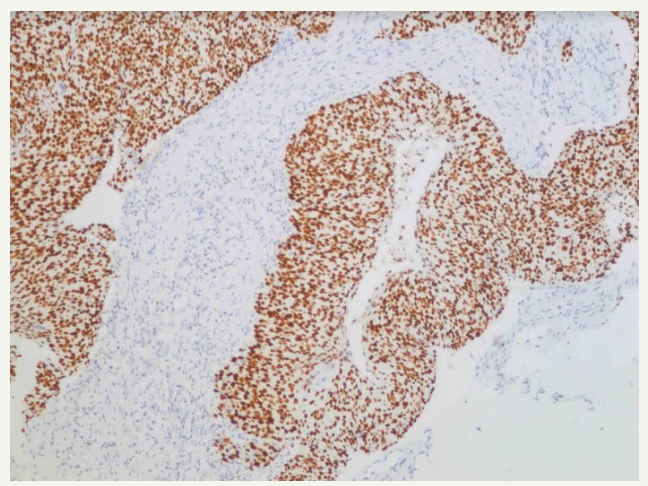

Figure 4: Positivity of the immunohistochemistry with the marker p63.

\section{Discussion}

Cervical cancer is the most frequently reported cancer in our country, with $14.9 \%$ of cases according to the "Analysis of Cancer in Peru in 2013" [4]. Eighty five percent are squamous cell carcinomas [5]. Gastrointestinal involvement is reported in $8 \%$ of patients with cervical cancer, the rectosigmoid region being the most frequently affected. The stomach is reported in $2 \%$ of patients and intestinal compromise is extremely rare. In a large series from 1943 to 2002 reported from Denmark, Norway, Finland, Sweden and 9 areas of the USA there were 85109 patients of which 54 had metastases to the SB [5]. Sixty-six percent of the patients with metastases to the SB had duodenal involvement [6]. Patients with cervical cancer and metastases to unusual sites are those with recurrent disease, especially after receiving radiotherapy. Theoretically the dissemination can occur by hematogenous, lymphatic or peritoneal spread. Christopherson et al suggest that tumor emboli may travel in a retrograd way from pelvic lymphatics to upper abdominal lynphadenopaties following to radiation fibrosis [7]. The lymphatic spread could be the way of dissemination to duodenum in our patient, because the compromise of retroperitoneal lymphadenopathies.

The most common clinical manifestations described are anemia, overt or occult gastrointestinal bleeding and intestinal obstruction. The diagnosis is confirmed by immunohistochemistry with markers CK5, p16, p63 [2]. Unfortunately, the HPV status of the Cervical Squamous Cells Carcinoma was not explored in our patient. These types of lesions are related to advanced stages of the disease, and support and palliative measures are usually the best therapeutic option. In cases of gastrointestinal hemorrhage there is limited information supporting the use of sclerotherapy, bipolar cautery of heater probe. In extreme, intractable cases arterial embolization can be tried. If the patient with duodenal metastases is in good general health and the tumor is known to be chemoresistant, surgery can be attempted [3]. Radiotherapy in patients with duodenal metastases can improve quality of life [3]. Our case has many similarities with other cases reported in the literature, regarding clinical presentation and the palliative approach offered to the patient. It is the seventh reported case of duodenal metastases of epidermoid carcinoma of the cervix, and the second documented with immunochemistry in our search $[3,7-$ 9].

\section{Conclusion}

Duodenal metastases from cervical cancer are extremely rare and must be suspected in patients with advanced stage squamous cell carcinoma who required radiotherapy. The most frequent manifestations are anemia, gastrointestinal bleeding and obstructive symptoms. Diagnosis is made with biopsy which can be endoscopic or surgical depending on the involved area, and should be confirmed by immunohistochemistry. Prognosis is poor and support measures are the usually the best options.

\section{References}

1. Schottenfeld D, Beebe Dimmer J, Vigneau F (2009) The epidemiology and pathogenesis of neoplasia in the small intestine. Ann Epidemiol 19(1): 58-69. 
2. Kanthan R, Senger JL, Diudea D, Kanthan S (2011) A review of duodenal metastases from squamous cell carcinoma of the cérvix presenting as an upper gastrointestinal bleed. World Surg Oncol 9: 113

3. Loualidi A, Spooren PF, Grubben MJ, Blomojous CE, Boey SH (2004) Duodenal metástasis: an uncommon cause of occult small intestinal bleeding. Neth J Med 62(6): 201-205.

4. Ramos WC, Venegas DR (2013) Análisis de la Situación del Cáncer en el Perú, 2013. Ministerio de Salud. Lima, Perú.

5. Chaturverdi A, Kleinerman R, Hildesheim A, Gilbert ES, Storm H, et al. (2009) Second cancers after squamous cell carcinoma and adenocarcinoma of the cervix. J Clin Oncol 27(6): 967-973.
6. Elkhatib I, Savides T, Fehmi A (2012) Duodenal metastasis of cervical adenosquamous carcinoma. Clinical Gastroenterology and Hepatology 10(7): A34.

7. Christopherson W, Voet R, Buchsbaum H (1985) Recurrent cervical cancer presenting as small bowel obstruction. Gynec Oncol 22(1): 109114.

8. Raphael JC, Ram TS, Pavamani S, Choudhaire L, Viswanathan PN (2011) Squamous cell carcinoma cérvix with metástasis to pyloduodenal región. J Cancer Res Ther 7(2): 183

9. Nag P, Bhandari V, Kausar M, Goyal H (2016) Duodenal metástasis from carcinoma cevix: an unusual presentation and review of literature. Clin Cancer Investig J 5(2): 166-168.

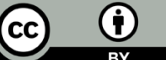

Creative Commons Attribution 4.0 International License

For possible submissions Click Here

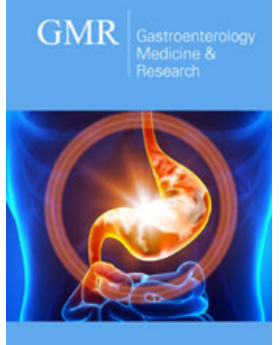

\section{Gastroenterology Medicine \& Research}

\section{Benefits of Publishing with us}

- High-level peer review and editorial services

- Freely accessible online immediately upon publication

- Authors retain the copyright to their work

- Licensing it under a Creative Commons license

- Visibility through different online platforms 